\title{
Effect of Alkali Activator on the Standard Consistency and Setting Times of Fly Ash and GGBS-Based Sustainable Geopolymer Pastes
}

\author{
M. Dineshkumar (iD) and C. Umarani (iD) \\ Division of Structural Engineering, Anna University, Chennai 600025, India \\ Correspondence should be addressed to M. Dineshkumar; dineshkumarstructural@gmail.com
}

Received 9 December 2019; Revised 9 October 2020; Accepted 3 December 2020; Published 22 December 2020

Academic Editor: Behzad Nematollahi

Copyright (C) 2020 M. Dineshkumar and C. Umarani. This is an open access article distributed under the Creative Commons Attribution License, which permits unrestricted use, distribution, and reproduction in any medium, provided the original work is properly cited.

\begin{abstract}
In this study, an attempt has been made to study the effect of alkali activator on the standard consistency and setting times of low calcium fly ash (FA) and ground granulated blast furnace slag (GGBS)- based sustainable geopolymer pastes. Different proportions of FA and GGBS were blended into mixes of geopolymer paste using sodium hydroxide (SH) and sodium silicate (SS) as alkaline activator solution (AAS). Tests on geopolymer pastes for consistency and initial and final setting times were carried out for three different $\mathrm{SH}$ : SS ratios of $1: 1,1: 2$, and $1: 3$ for both $2.5 \mathrm{M}$ (molarity) and $5.0 \mathrm{M}$ of SH concentration. While increasing the molarity of $\mathrm{SH}$, both consistency and setting time decreased. For all the blended binder mix, the setting time decreases with an increase in the quantity of SS in the alkali activator solution. An increase in the amount of GGBS content in the geopolymer blended binder mix increases the consistency and decreases the setting time. For both $2.5 \mathrm{M}$ and $5 \mathrm{M}$ blended geopolymer mixes, a decrease in the percentage of GGBS and an increase in the percentage of FA increased the setting time. Microstructural studies such as X-ray fluorescence analysis (XRF), X-ray diffraction (XRD), scanning electron microscopy (SEM), and Fourier transform infrared spectroscopy (FT-IR) analyses were carried out, and the results are presented. The FT-IR spectra for the blended binder mixes demonstrated the formation of geopolymerization and the presence of the functional groups.
\end{abstract}

\section{Introduction}

Cement as a binder material plays a vital role in building construction. Cement is now used in all construction works either as a plaster or as an ingredient in producing concrete. In cement manufacturing, India is the second largest producer of cement in the world. The amount of cement produced in India in the year 2017 is 270000 tons [1]. One ton of cement production results in the emission of nearly 0.94 tons of $\mathrm{CO}_{2}$ [2]. An increase in the consumption of cement in construction activities leads to the emission of an enormous amount of $\mathrm{CO}_{2}$ and the depletion of a large number of earthen resources, which is a major raw material for cement manufacturing. To overcome the consequence of cement production, it is essential to look for an alternative material which reduces the usage of cement.

Geopolymer and the concept of geopolymerization are well accepted by many scientists $[3,4]$, and in the recent past, many studies on geopolymer cement and geopolymer concrete have been carried out $[5,6]$. While comparing the production costs of different construction materials by considering either the eco-taxes energy or actual $\mathrm{CO}_{2}$ emission, it has been proved that the geopolymer concrete involves the least production cost, next to wood [5]. Recent research on geopolymer concrete includes the development of ultra-high-performance geopolymer concrete [7]. Also, researchers have reported on ultra-high-performance concrete incorporating copper slag as fine aggregate [8], etc. Although geopolymer concrete is an extremely powerful alternative for sustainable material, the present application on buildings and other structural components is limited due to the lack of structural design and codes [9].

Though the developments and advancements are rapid on the research side, the use of geopolymer concrete is not that much encouraging in real life. This is mainly due to the nonexistence of codal provisions with regard to the 
procedure for the design of geopolymer concrete and lack of information about the basic properties of geopolymer concrete. This research addresses two issues: (i) effect of alkali activator on the standard consistency and setting times of geopolymer concrete and (ii) use of FA and GGBS, the industrial by-products in producing geopolymer concrete.

The role of silica and alumina is to impart the strength and setting property to the cement. Binders could be produced by a polymeric reaction of alkaline liquids with silicon and aluminium in source materials of the byproducts such as FA, GGBS, and rice husk ash $[5,10]$. The mineral admixtures such as FA, GGBS, metakaolin, and rice husk ash can be used in concrete to replace the cement to obtain concrete with better performance and good engineering properties [11]. The presence of alumina and silica in industrial wastes such as FA and GGBS makes it possible to use the industrial wastes as alternatives to cement. Over 64.57 million tons of FA were produced in 2017-2018, as reported by Central Electricity Authority, New Delhi, India [12].

The AAS can be prepared by using either SH and SS or potassium hydroxide (PH) and potassium silicate (PS). But in most of the applications, SH and SS are commonly used. While comparing the use of $\mathrm{PH}$ and PS with the use of $\mathrm{SH}$ and SS, the former shows a lesser capacity to liberate silicate and aluminium monomers [13]. Also, the cost of SH and SS is cheaper when compared to PH and PS.

Kumar et al. [9] report that alumina and silica present in the FA and GGBS can be dissociated by the alkaline attack with the addition of AAS. SH and SS have been used as AAS. Due to this alkaline solution, an aluminosilicate reaction has been triggered, leading to the formation of geopolymer concrete and corresponding hydroxides. Further, these products have undergone a polymerization reaction through gel formation, where hardening of materials takes place.

FA and GGBS blended pastes display high reaction and mechanical strength, whereas this does not take place in pure FA mix. Pure GGBS mix has the highest heat release and high compressive strength [14]. Increase in the $\mathrm{Na}_{2} \mathrm{O}$ increases the $\mathrm{pH}$ value. On the other hand, increase in the $\mathrm{SiO}_{2}$ concentration reduces the $\mathrm{pH}$ value. Moreover, the AAS influences setting time [15]. FA-based geopolymer with GGBS is suitable for the production of ambient curing geopolymer concrete. The use of GGBS eliminates heat curing in geopolymer concrete [16].

100\% GGBS mix has a durable and robust cross-linked alumina silicate polymer structure. 100\% FA mix has a lower performance due to the low reactivity of FA particles [17]. The use of nanosilica and steel fiber in geopolymer concrete affects the fresh state properties; however, it improves the bond strength and flexural strength [18]. Use of class F-FA displays superior performance when compared to the use of class C-FA in geopolymer concrete [19].

In this study, an attempt has been made to study the effect of alkali activator on the standard consistency and setting times of low calcium FA and GGBS- based sustainable geopolymer pastes.

\section{Materials and Experimental Details}

This research addressed two issues: (i) effect of alkali activator on the standard consistency and setting times of geopolymer concrete and (ii) use of FA and GGBS, the industrial by-products in producing geopolymer concrete. Experiments were conducted on geopolymer paste with (a) varying percentages of FA and GGBS, (b) with varying molarity, $2.5 \mathrm{M}$ and $5 \mathrm{M}$ of $\mathrm{SH}$, and (c) with three different SH:SS ratios of $1: 1,1: 2$, and $1: 3$. XRF, SEM, and FT-IR analyses were carried out and the results are presented. FA, GGBS, and AAS were used for conducting the experimental investigation on standard consistency and setting times of SH- and SS-activated FA- and GGBS-based geopolymer for producing sustainable concrete.

2.1. Fly Ash (FA). FA is a finely divided residue that results from pulverized coal/lignite combustion and is transported from the combustion chamber by exhaust gases. The FA used was low calcium class F fly ash (FA); it was obtained from the Thermal Power Plant, Ennore.

2.2. Ground Granulated Blast Furnace Slag (GGBS). Ground granulated blast furnace slag (GGBS) was obtained by quenching molten iron slag (a by-product of iron and steel-making) from a blast furnace in water or steam to produce a glassy, granular product. It was further dried and ground into a fine powder. Ground granulated blast furnace slag (GGBS) is a by-product of steel industries obtained from Astra Chemicals, Chennai.

2.3. Alkaline Activator Solution (AAS). SH in the form of flakes was obtained from Sisco Research Laboratory Pvt. Ltd., Mumbai. SS was obtained from Kiran Global Chem Pvt. Ltd, Chennai. The chemical composition of SS was $14.52 \%$ of $\mathrm{Na}_{2} \mathrm{O}$ and $32.29 \%$ of $\mathrm{SiO}_{2}$ by mass.

2.4. X-Ray Fluorescence Analysis (XRF). The chemical compositions of FA and GGBS were determined using X-ray fluorescence analysis from the National Centre for Earth Science Studies, Trivandrum, and the results are given in Table 1.

2.5. X-Ray Diffraction (XRD) Analysis. The X-ray diffraction (XRD) powder X-ray diffraction pattern of FA and GGBS was carried out on Bruker D2 Phaser X-ray diffractometer and recorded using $\mathrm{Cu}-\mathrm{K}\left(1.5418 \mathrm{~A}^{\circ}\right)$ radiation in the $2 \mathrm{~h}$ range of $10-80$ with a step size $0.02^{\circ} / 1$ s. XRD pattern of FA shown in Figure 1(a) demonstrates the presence of the crystalline phase, which is indicated by sharp peaks of mullite (alumina silicate) and quartz [20]. XRD pattern of 
TABle 1: Chemical composition of FA and GGBS from XRF analysis.

\begin{tabular}{lccccccccccc}
\hline Oxide (\%) & $\mathrm{SiO}_{2}(\%)$ & $\mathrm{Al}_{2} \mathrm{O}_{3}(\%)$ & $\mathrm{Fe}_{2} \mathrm{O}_{3}(\%)$ & $\mathrm{TiO}_{2}(\%)$ & $\mathrm{K}_{2} \mathrm{O}(\%)$ & $\mathrm{CaO}(\%)$ & $\mathrm{MgO}(\%)$ & $\mathrm{P}_{2} \mathrm{O}_{5}(\%)$ & $\mathrm{SO}_{3}(\%)$ & $\mathrm{MnO}^{(\%)}$ & $\mathrm{Total}(\%)$ \\
\hline FA & 60.42 & 31.06 & 3.34 & 2.02 & 0.95 & 0.93 & 0.46 & 0.41 & 0.10 & 0.03 & 99.82 \\
GGBS & 34.42 & 16.62 & 0.64 & 0.84 & 0.31 & 38.27 & 5.99 & 0.00 & 1.57 & 1.04 & 99.93 \\
\hline
\end{tabular}

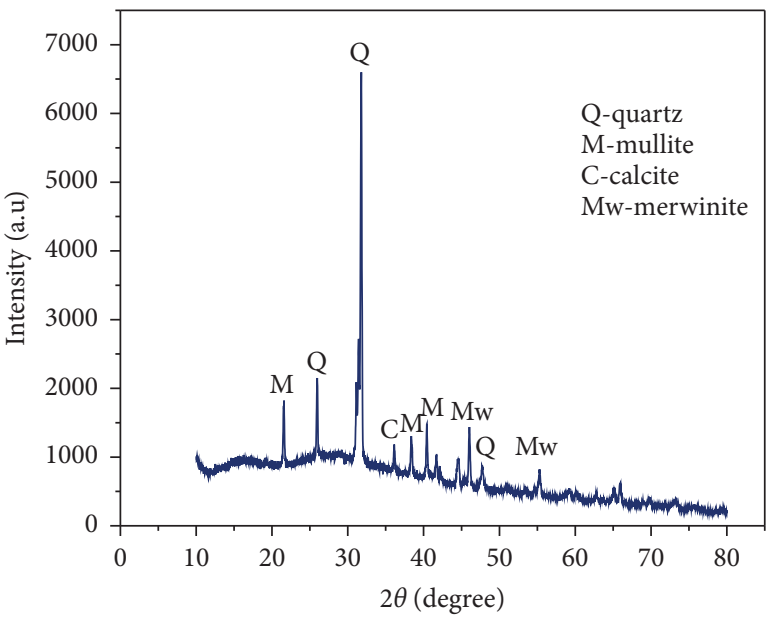

_ Fly ash

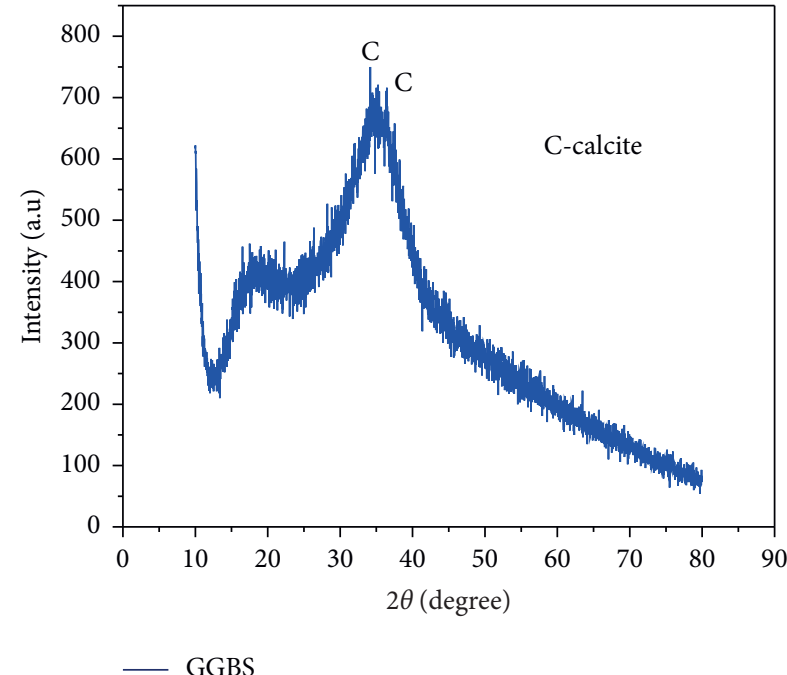

(b)

Figure 1: XRD patterns of (a) FA and (b) GGBS.

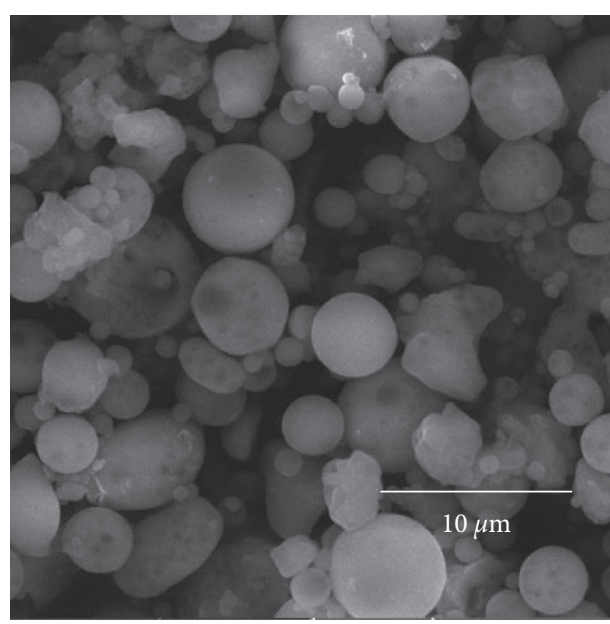

(a)

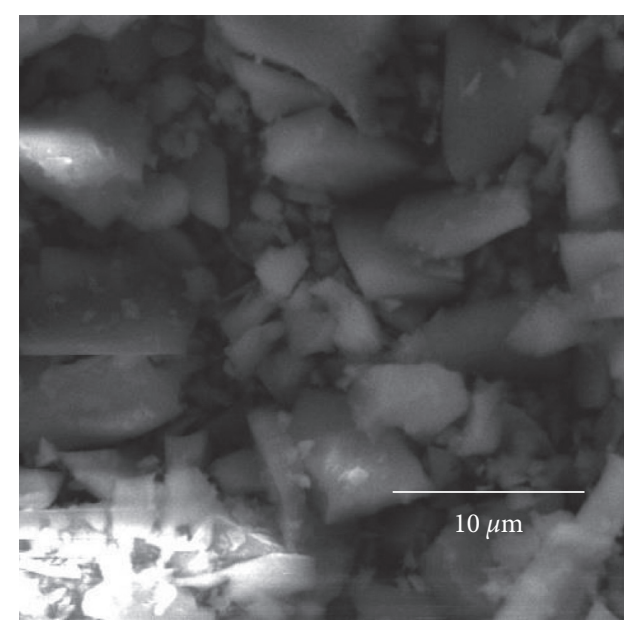

(b)

FIgURE 2: SEM images of (a) FA and (b) GGBS.

GGBS shown in Figure 1(b) implies that GGBS reveals an amorphous hump at around $28^{\circ}-31^{\circ}$ and $10^{\circ}-20^{\circ}$. It confirms the presence of high vitreous calcite content in the sample [21].

2.6. Scanning Electron Microscopy (SEM) Analysis. Scanning electron microscopy analyses were performed using a VEGA3 TESCAN microscope for studying the microstructural properties of FA and GGBS. The SEM images of FA and GGBS are presented in Figure 2(a) and 2(b), respectively. The FA particles show a spherical shape with rounded angularity, whereas the GGBS particles show a straight, flaky, elongated shape with sharp-edged angularity and rough surface texture.

2.7. Blended Binder Mix. The FA and GGBS were mixed in various percentages such as $(0: 100),(10: 90),(30: 70),(50$ : $50),(70: 30),(90: 10)$, and $(100: 0)$ and used as blended 
TABle 2: Percentage of consistency and setting times of blended geopolymer paste.

\begin{tabular}{|c|c|c|c|c|}
\hline Mix symbol & Mixture detail & Consistency (\%) & Initial setting time ( $\mathrm{min}$ ) & Final setting time $(\mathrm{min})$ \\
\hline A & FA-00-GGBS-100, 2.5M-1:1 & 35 & 150 & 390 \\
\hline $\mathrm{B}$ & FA-00-GGBS-100, $2.5 \mathrm{M}-1: 2$ & 34 & 100 & 370 \\
\hline $\mathrm{C}$ & FA-00-GGBS-100, 2.5M-1:3 & 34 & 35 & 280 \\
\hline $\mathrm{D}$ & FA-00-GGBS-100, 5.0M-1:1 & 32 & 35 & 160 \\
\hline $\mathrm{E}$ & FA-00-GGBS-100, 5.0M-1:2 & 31 & 25 & 85 \\
\hline $\mathrm{F}$ & FA-00-GGBS-100, 5.0M-1:3 & 31 & 15 & 60 \\
\hline G & FA-10- GGBS-90, 2.5M-1:1 & 35 & 160 & 435 \\
\hline $\mathrm{H}$ & FA-10-GGBS-90, 2.5M-1:2 & 33 & 120 & 395 \\
\hline I & FA-10-GGBS-90, 2.5M-1:3 & 33 & 40 & 335 \\
\hline $\mathrm{J}$ & FA-10-GGBS-90, 5.0M-1:1 & 32 & 45 & 220 \\
\hline $\mathrm{K}$ & FA-10-GGBS-90, 5.0 M-1:2 & 31 & 40 & 140 \\
\hline $\mathrm{L}$ & FA-10-GGBS-90, $5.0 \mathrm{M}-1: 3$ & 30 & 35 & 90 \\
\hline M & FA-30-GGBS-70, 2.5M-1:1 & 33 & 165 & 440 \\
\hline $\mathrm{N}$ & FA-30-GGBS-70, 2.5M-1:2 & 33 & 135 & 395 \\
\hline $\mathrm{O}$ & FA-30-GGBS-70, 2.5M-1:3 & 32 & 45 & 340 \\
\hline $\mathrm{P}$ & FA-30- GGBS-70, 5.0 M-1:1 & 31 & 55 & 340 \\
\hline Q & FA-30-GGBS-70, $5.0 \mathrm{M}-1: 2$ & 30 & 45 & 155 \\
\hline $\mathrm{R}$ & FA-30-GGBS-70, $5.0 \mathrm{M}-1: 3$ & 30 & 40 & 105 \\
\hline S & FA-50-GGBS-50, 2.5M-1:1 & 33 & 170 & 480 \\
\hline $\mathrm{T}$ & FA-50-GGBS-50, 2.5M-1:2 & 31 & 140 & 430 \\
\hline $\mathrm{U}$ & FA-50-GGBS-50, 2.5M-1:3 & 31 & 50 & 350 \\
\hline $\mathrm{V}$ & FA-50-GGBS-50, 5.0 M-1:1 & 31 & 55 & 365 \\
\hline $\mathrm{W}$ & FA-50-GGBS-50, 5.0 M-1:2 & 30 & 50 & 200 \\
\hline $\mathrm{X}$ & FA-50-GGBS-50, $5.0 \mathrm{M}-1: 3$ & 30 & 45 & 140 \\
\hline $\mathrm{Y}$ & FA-70-GGBS-30, 2.5M-1:1 & 33 & 180 & 485 \\
\hline $\mathrm{Z}$ & FA-70-GGBS-30, 2.5M-1:2 & 31 & 140 & 450 \\
\hline AA & FA-70-GGBS-30, 2.5M-1:3 & 31 & 50 & 370 \\
\hline $\mathrm{AB}$ & FA-70-GGBS-30, 5.0 M-1:1 & 31 & 75 & 365 \\
\hline $\mathrm{AC}$ & FA-70-GGBS-30, $5.0 \mathrm{M}-1: 2$ & 29 & 60 & 230 \\
\hline $\mathrm{AD}$ & FA-70-GGBS-30, $5.0 \mathrm{M}-1: 3$ & 29 & 50 & 150 \\
\hline $\mathrm{AE}$ & FA-90-GGBS-10, 2.5M-1:1 & 32 & 190 & 580 \\
\hline $\mathrm{AF}$ & FA-90-GGBS-10, 2.5M-1:2 & 30 & 145 & 550 \\
\hline AG & FA-90-GGBS-10, 2.5M-1:3 & 30 & 55 & 380 \\
\hline $\mathrm{AH}$ & FA-90-GGBS-10, 5.0 M-1:1 & 30 & 85 & 390 \\
\hline AI & FA-90-GGBS-10, $5.0 \mathrm{M}-1: 2$ & 29 & 65 & 280 \\
\hline AJ & FA-90-GGBS-10, 5.0 M-1:3 & 28 & 60 & 160 \\
\hline $\mathrm{AK}$ & FA-100-GGBS-0, 2.5M-1:1 & 32 & 210 & 725 \\
\hline $\mathrm{AL}$ & FA-100-GGBS-0, 2.5M-1:2 & 30 & 150 & 570 \\
\hline $\mathrm{AM}$ & FA-100-GGBS-0, 2.5M-1:3 & 29 & 90 & 450 \\
\hline $\mathrm{AN}$ & FA-100-GGBS-0, 5.0 M-1:1 & 29 & 100 & 460 \\
\hline $\mathrm{AO}$ & FA-100-GGBS-0, $5.0 \mathrm{M}-1: 2$ & 28 & 70 & 320 \\
\hline $\mathrm{AP}$ & FA-100-GGBS-0, 5.0 M-1:3 & 28 & 65 & 200 \\
\hline
\end{tabular}

binder mix to produce geopolymer paste. AAS was obtained by mixing $\mathrm{SH}$ and SS. Studies were carried out for $2.5 \mathrm{M} \mathrm{SH}$ and $5 \mathrm{M}$ SH concentrations. Three different $\mathrm{SH}$ : SS ratios were considered, which include $1: 1,1: 2$, and $1: 3$ for both $2.5 \mathrm{M} \mathrm{SH}$ and 5.0 M SH cases. The SH solution prepared with $2.5 \mathrm{M} \mathrm{SH}$ solution consists of $2.5 \times 40=100 \mathrm{~g}$. $100 \mathrm{~g}$ of $\mathrm{SH}$ flakes was dissolved in water up to 1 litre. The details of various mix proportions of blended geopolymer paste are shown in Table 2.

2.8. Preparation of Specimens. Consistency is the ability of a freshly mixed cement paste or mortar or binder mix to flow.
The consistency of cement is also called a standard consistency or normal consistency.

$400 \mathrm{~g}$ of dry blended mix of FA and GGBS in each combination (out of different combinations such as $(0: 100)$, (10:90), (30:70), (50:50), (70:30), (90:10), and (100:0) was weighed, and $25 \%$ by weight of AAS was added to prepare the geopolymer paste. The standard consistency test was carried out using the Vicat apparatus in the laboratory as per the IS 4031 (Part 4)-1988 [22]. The Vicat plunger would stop penetrating around $5-7 \mathrm{~mm}$ before it reaches the bottom surface. The standard consistency test was performed to find the AAS percentage required to produce a geopolymer paste. 


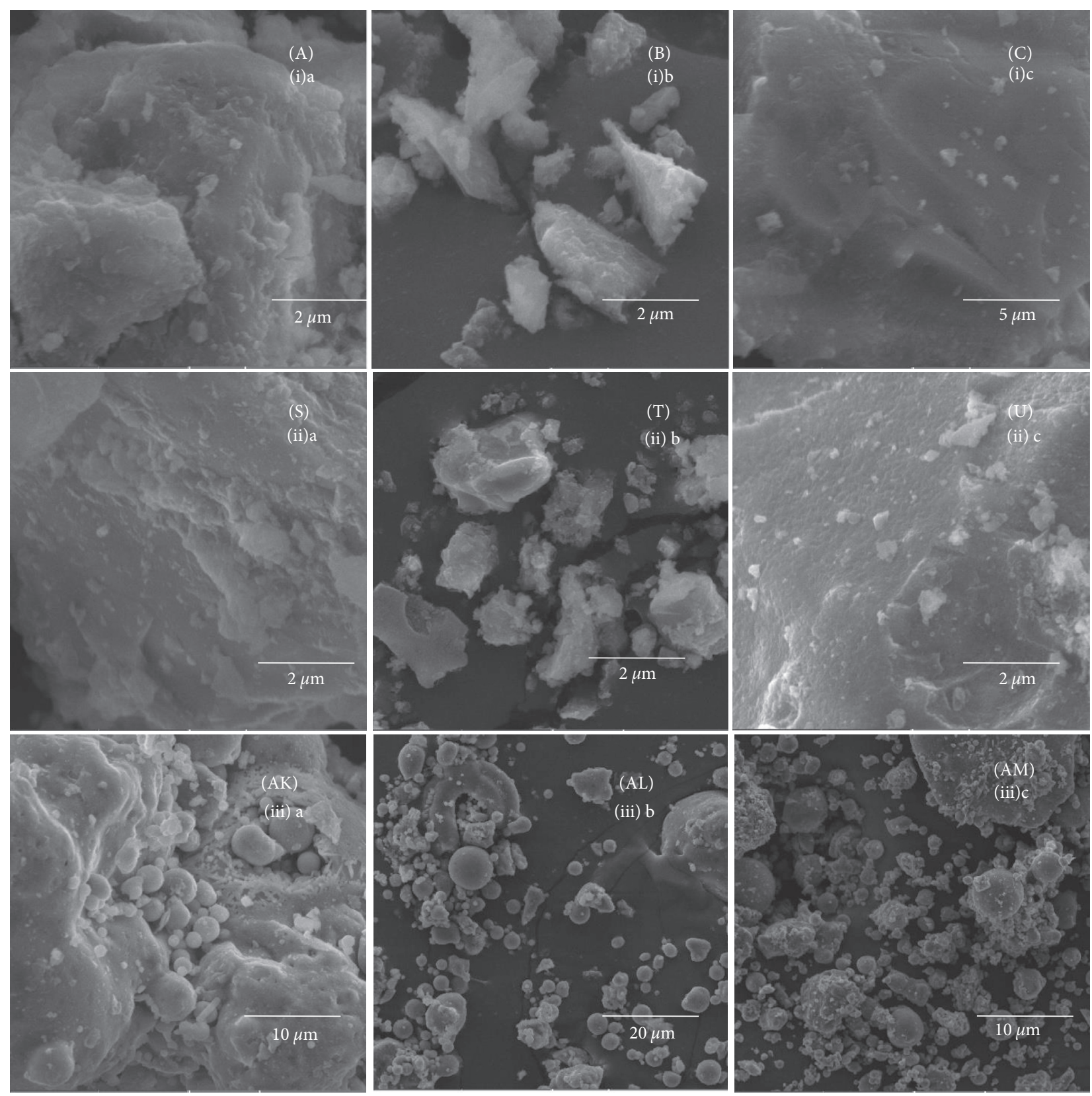

Figure 3: SEM images of geopolymer paste with $2.5 \mathrm{M}$ of SH.

Trials were conducted with $1 \%$ increment of AAS until the standard consistency was reached. Based on the trials, with varying percentages of AAS, pastes were prepared to find the required (weight) amount of AAS for achieving the standard consistency.

Determination of initial and final setting times was performed according to IS: 4031 (Part 5)-1988 [23], which requires preparation of geopolymer paste by adding 0.85 times of AAS of standard consistency.

For the initial setting time, a $1 \mathrm{~mm}$ square needle is used to penetrate into the paste at every 10 min intervals until the index scale shows $5+0.5 \mathrm{~mm}$ from the bottom of the mould.
For determining the final setting time, the needle was replaced with an annular attachment. Readings were noted at every $30 \mathrm{~min}$ interval; the attachment was dropped on the paste surface till the annular attachment failed to make any impression [23].

\section{Results and Discussion}

3.1. Consistency of Geopolymer Paste. The values of standard consistency for various combinations of geopolymer blended binder paste and comparison of blended binder mix to the percentage of consistency for $2.5 \mathrm{M}$ and $5 \mathrm{M}$ of $\mathrm{SH}$ and 

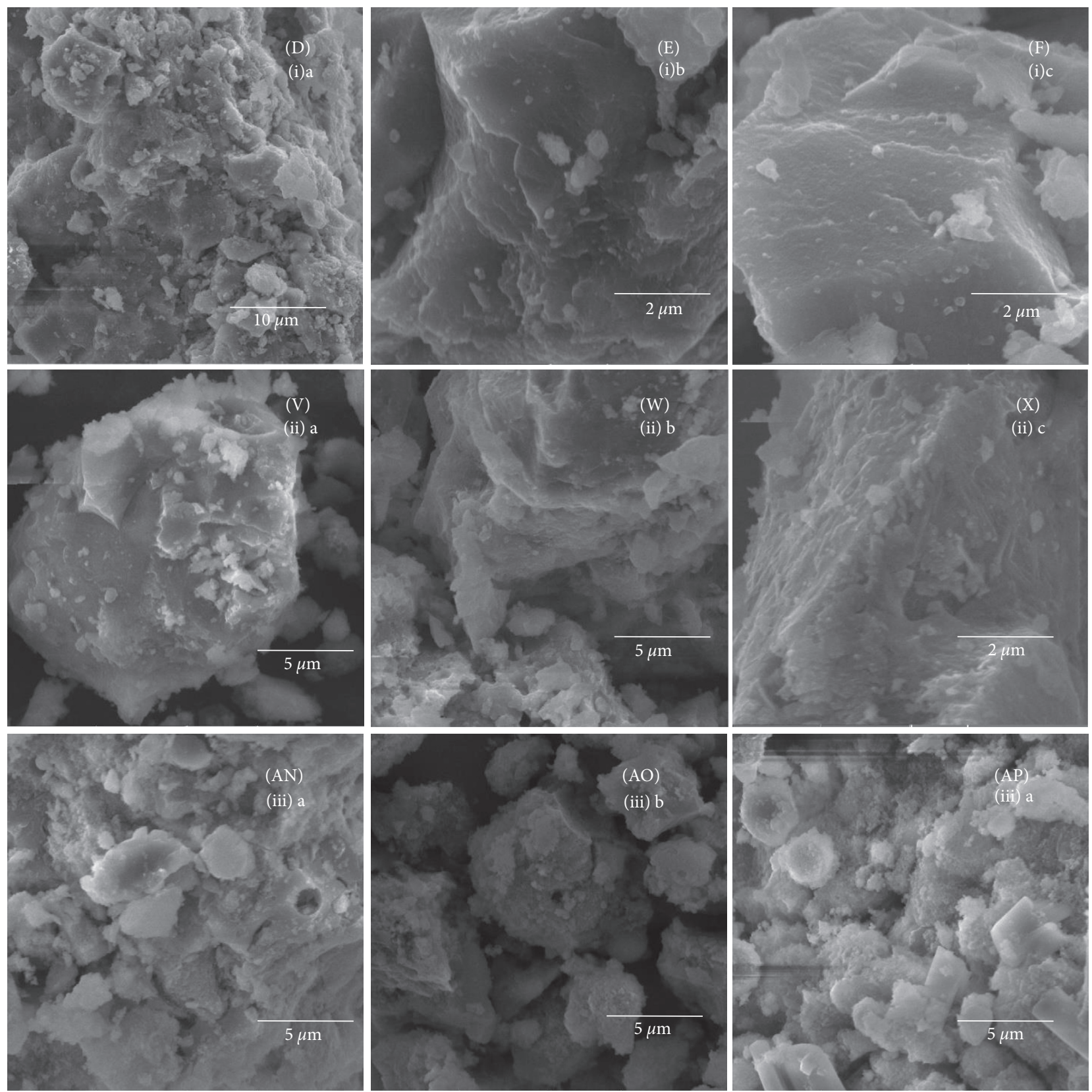

FIGURE 4: SEM images of geopolymer paste with $5 \mathrm{M}$ of $\mathrm{SH}$.

SH:SS proportions were $1: 1,1: 2$, and $1: 3$ which are tabulated in Table 2 .

In Table 2, mix description is given, which is demonstrated as follows:

(1) FA-X-GGBS-Y, 2.5 M-1:1 represents a mix containing $\mathrm{X} \%$ of FA (fly ash), Y\% of ground granulated blast furnace slag (GGBS), 2.5 molarity, and 1 part of SH (sodium hydroxide) and 1 part of SS (sodium silicate)

(2) FA-X-GGBS-Y, 5.0 M-1:2 represents a mix containing $\mathrm{X} \%$ of fly ash, Y\% of GGBS, 5.0 molarity, and 1 part of $\mathrm{SH}$ and 2 parts of SS
The 100\% FA-based geopolymer binder requires a lesser amount of AAS to attain the consistency as specified in IS 4031 (Part 4)-1988 for both $2.5 \mathrm{M}$ and $5 \mathrm{M}$ mixes. The $100 \%$ GGBS-based geopolymer binder requires more amount of AAS to attain the consistency as specified in IS 4031 (Part 4)1988 for both $2.5 \mathrm{M}$ and $5 \mathrm{M}$ mixes. At intermediate mixes, the addition of GGBS content increases the normal consistency value. This is because of the nature of the FA shape factor and its lower residual friction. This would lead to the easy movement of Vicat plunger at lower alkaline activator content and GGBS with higher internal residual friction, thereby consuming more AAS to achieve the standard consistency. When the comparison of blended mix with 


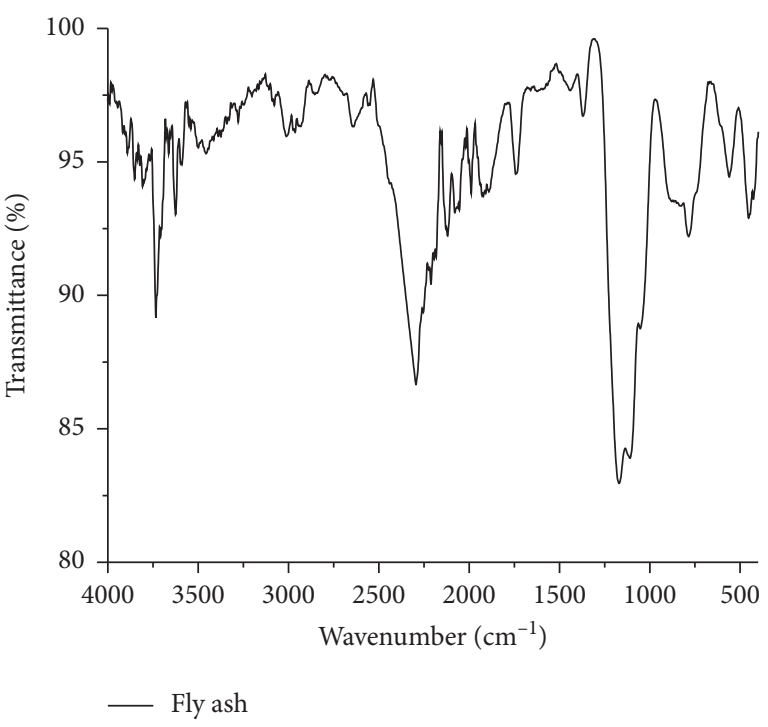

FIgURE 5: FT-IR image of FA.

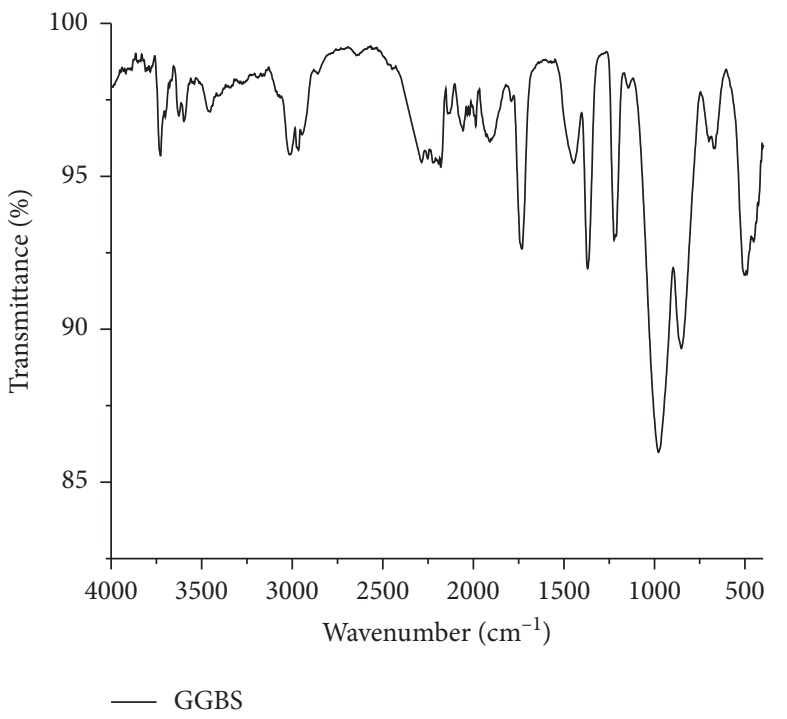

Figure 6: FT-IR image of GGBS.

respect to the proportion $\mathrm{SH}$ : SS is considered, the consistency decreases with an increase in SS percentage for both $2.5 \mathrm{M}$ and $5 \mathrm{M}$ blended mixes.

3.2. Initial Setting Time. The initial setting times of blended binder geopolymer paste with various proportions of FA and GGBS are given in Table 2 and the comparison of initial setting times for various blended binder mix with $\mathrm{SH}$ : SS proportions of $1: 1,1: 2$, and $1: 3$ for $2.5 \mathrm{M}$ and $5 \mathrm{M}$ of $\mathrm{SH}$ is presented.

For all the blended binder mix (FA-GGBS mix) consisting of various ratios, the initial setting time decreases
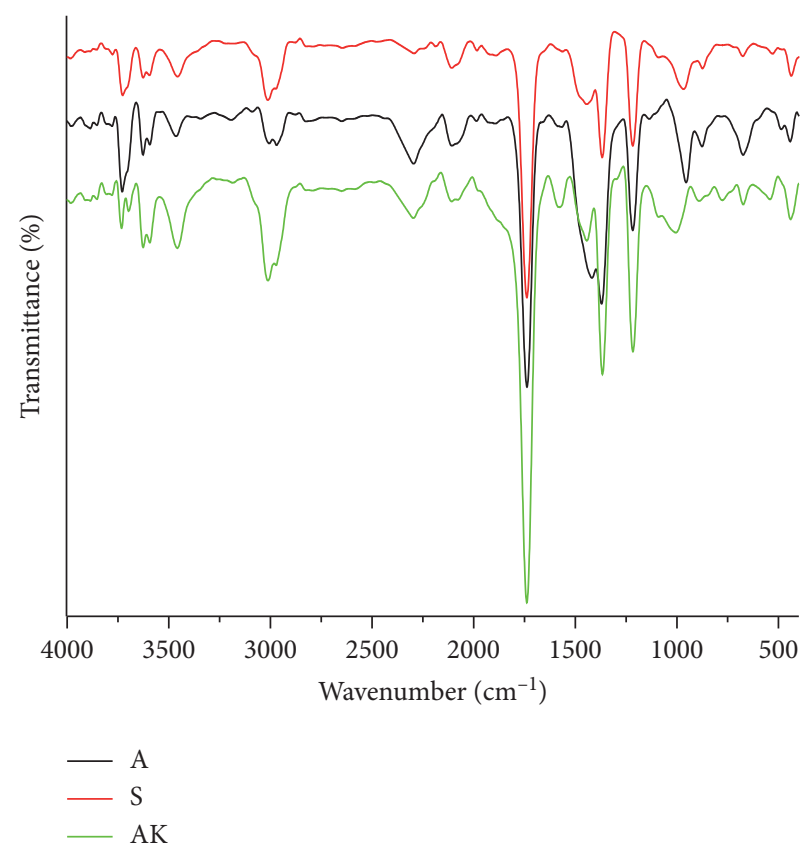

Figure 7: FT-IR image of $2.5 \mathrm{M}$ and $1: 1$ of $\mathrm{SH}: \mathrm{SS}$.

with an increase in the concentration of SS in the AAS used. For both $2.5 \mathrm{M}$ and $5 \mathrm{M}$ blended binder geopolymer mixes, a decrease in the percentage of GGBS and an increase in the percentage of FA increase the initial setting time.

For the blended binder mixes E and F, GGBS was 100\% in the $5 \mathrm{M}$ of $\mathrm{SH}$ solution with $\mathrm{SH}$ : SS proportions of $1: 2$ and $1: 3$, and the initial setting time had occurred below $30 \mathrm{~min}$. So, these two mixes do not satisfy the provisions of the code IS: 4031 (Part 5)-1988, whereas the corresponding mix with the proportion of SH:SS 1:1 satisfies the codal provisions for initial setting time.

3.3. Final Setting Time. The final setting time behaviour considered in the study of geopolymer pastes for various combinations of blended binder mix is given in Table 2 and comparison of final setting times for various blended binder mix with $\mathrm{SH}: \mathrm{SS}$ proportions of $1: 1,1: 2$, and $1: 3$ for $2.5 \mathrm{M}$ and $5 \mathrm{M}$ of $\mathrm{SH}$ is presented.

The final setting time clearly shows that increase in the content (\%) of FA increases the final setting time of the blended binder mix. In contrast, the increase in the content of GGBS decreases the final setting time of the blended binder mix. At intermediate blended binder mixes, a higher percentage of GGBS decreases the final setting time. It is evident that an increase in the molar concentration of AAS in $\mathrm{SH}$ and $\mathrm{SH}$ : $\mathrm{SS}$ decreases the final setting time. For the blended binder mix (AK) FA $100 \%$ in the $2.5 \mathrm{M}$ of $\mathrm{SH}$ solution for the proportion of $1: 1$ in SH: SS, the final setting time occurred after $600 \mathrm{~min}$. So, the above mix does not satisfy the provisions given in the code IS: 4031 (Part 5)1988. 


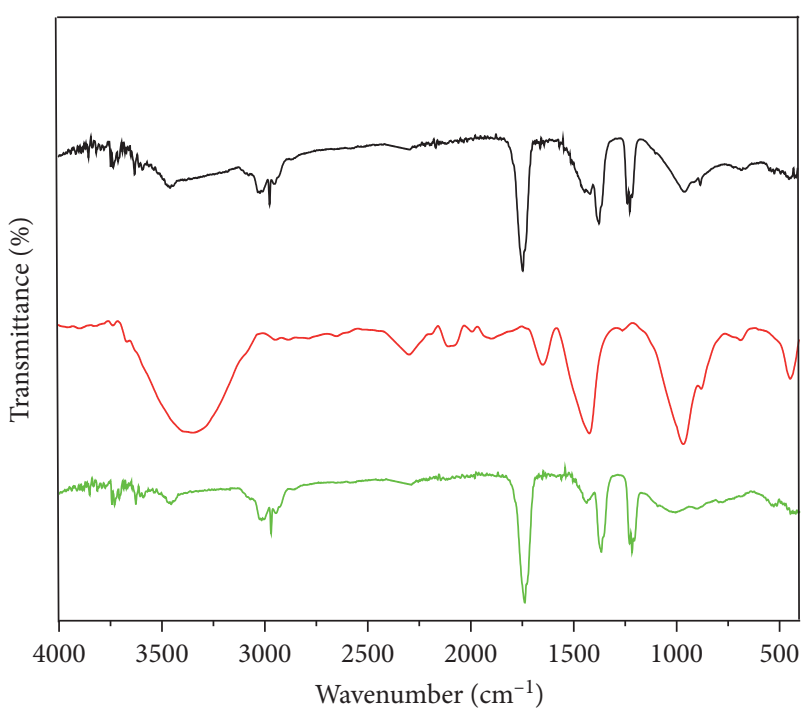

$-\mathrm{B}$

$-\mathrm{T}$

$-\mathrm{AL}$

FIGURE 8: FT-IR image of $2.5 \mathrm{M}$ and $1: 2$ of SH: SS.

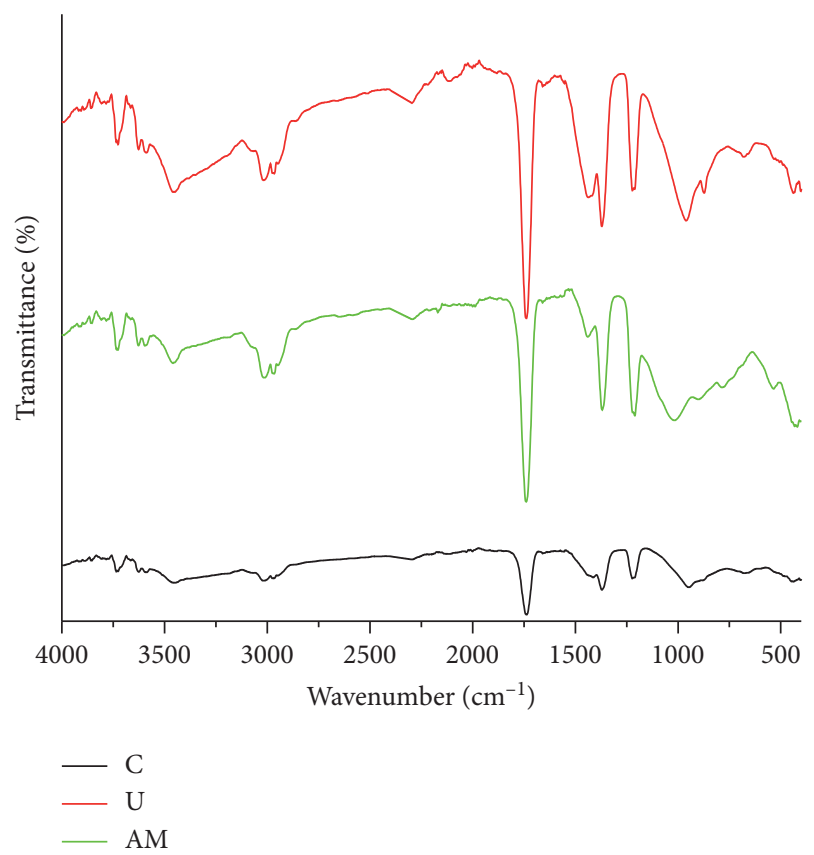

FIgURE 9: FT-IR image of $2.5 \mathrm{M}$ and $1: 3$ of $\mathrm{SH}$ : SS.

3.4. Microstructural Studies. Scanning electron microscopy (SEM) was performed using VEGA3 TESCAN microscope for the microstructural properties of various geopolymer blended binder mixes after 28 days of casting at ambient condition. Figures 3 and 4 show the SEM images of geopolymer blended pastes of $\mathrm{A}, \mathrm{B}, \mathrm{C}, \mathrm{D}, \mathrm{E}, \mathrm{F}, \mathrm{AK}, \mathrm{AL}, \mathrm{AM}, \mathrm{AN}$, AO, AP, S, T, U, V, W, and X.

The SH:SS proportions were $1: 1,1: 2$, and $1: 3$, and different proportions of geopolymer blended binder mixes

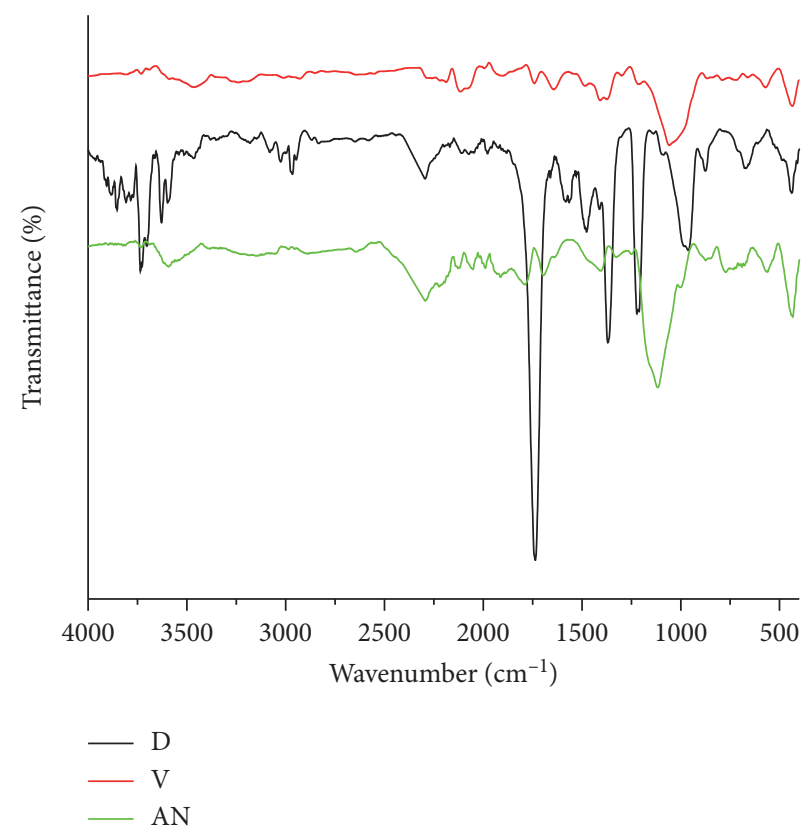

FIgURE 10: FT-IR image of $5 \mathrm{M}$ and $1: 1$ of $\mathrm{SH}: \mathrm{SS}$.

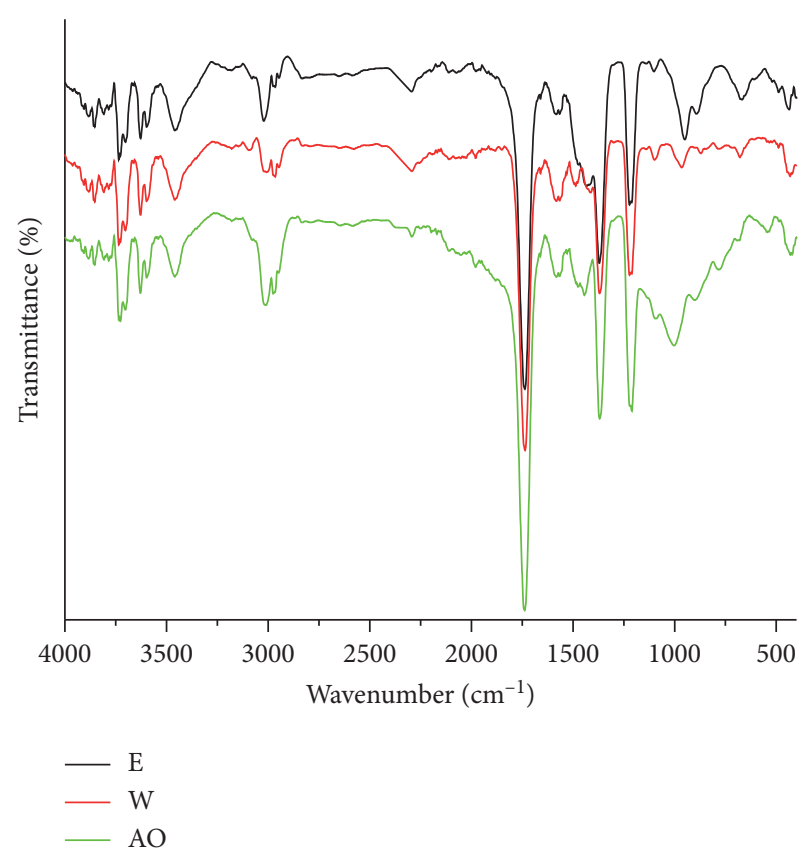

FIgURE 11: FT-IR image of $5 \mathrm{M}$ and $1: 2$ of SH:SS.

were studied. The spherical shape in the morphology images of $2.5 \mathrm{M}$ of $\mathrm{SH}$ is clearly visible. While comparing the SEM image represented in Figure 3 (i) a-(A), 3 (ii) a-(S), and 3 (iii) a- $(\mathrm{AK})$, the presence of unreacted FA particles was found in the blended binder mix with $100 \%$ FA as shown in Figure 3 (iii) a-(AK). While comparing Figure 3 (iii) a-(AK), 3 (iii) $\mathrm{b}-(\mathrm{AL})$, and 3 (iii) $\mathrm{c}-(\mathrm{AM})$, it was found that with an increase in SS solution, there is an increase in unreacted FA particles $[24,25]$. For the mixes AL and AM shown in Figure 3, it was 


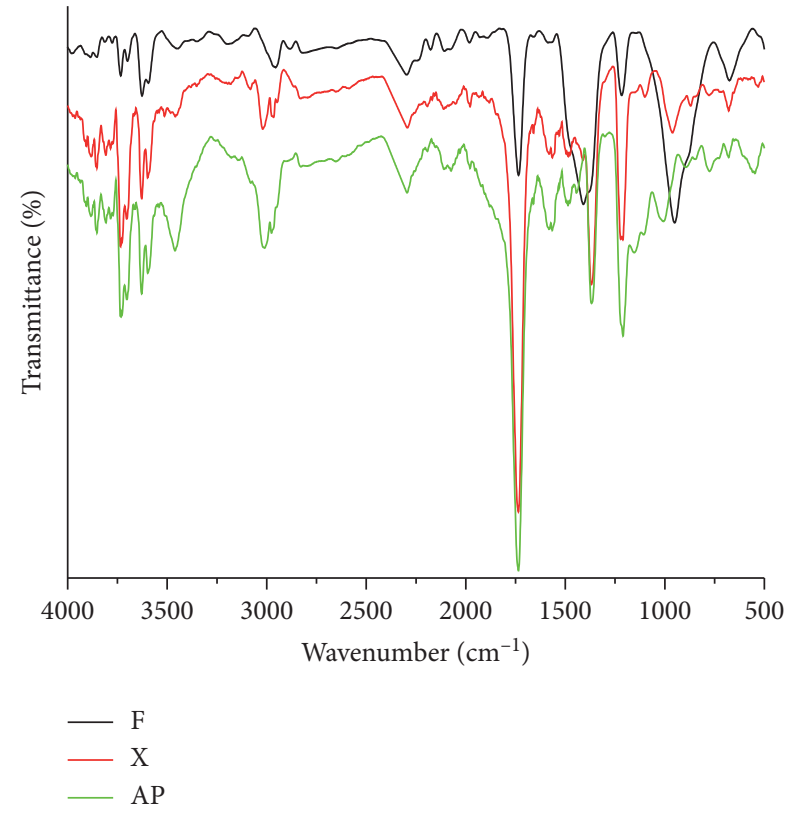

FIgURE 12: FT-IR image of $5 \mathrm{M}$ and $1: 3$ of $\mathrm{SH}: \mathrm{SS}$.

confirmed that the quantity of SH taken was not sufficient to forward the reaction for a high quantity of FA and increased SS. In the case of morphological images of $5 \mathrm{M}$ of $\mathrm{SH}$ samples, there were no such spherical or any specific geometrical particles observed. This is due to the addition of a high concentration of alkali, which can react with all the silica present in the silicates when the molarity of SH increases. As seen in Figure 4, only images of agglomerated particles were obtained.

3.5. FT-IR Analysis. FT-IR analysis of all the FA- and GGBSbased geopolymer samples and pure samples was carried out to identify the functional groups present and also to confirm the occurrence of the reaction. FT-IR analysis for all the samples of geopolymer mix was carried out after 28 days from the date of casting and the results are presented.

In the spectrum of both FA and GGBS as represented in Figures 5 and 6 , peaks obtained at $1171 \mathrm{~cm}^{-1}$ and $966 \mathrm{~cm}^{-1}$ correspond to $\mathrm{Si}-\mathrm{O}$ in silica and Al-O in alumina, which is comparatively reduced or vanished in some samples of geopolymer after the occurrence of the reaction [26].

The spectrum of geopolymer samples of Figures 7-11 shows a peak appeared at $460 \mathrm{~cm}^{-1}$, which is due to the presence of Si-O-Si bending vibration and the peaks observed in the region of $3450 \mathrm{~cm}^{-1}$ are due to the $\mathrm{O}-\mathrm{H}$ stretching, and subsequently, one more peak obtained at $1735 \mathrm{~cm}^{-1}$ is caused by the bending vibrations of $\mathrm{H}-\mathrm{O}-\mathrm{H}$ [24]. It confirms that a water molecule is embedded in the pores on the surface of the geopolymer materials. The $\mathrm{O}-\mathrm{H}$ stretching also means the presence of alkali hydroxide, which is formed during the addition of $\mathrm{SH}$. The band measured at $1450 \mathrm{~cm}^{-1}$ indicates the presence of O-C-O from carbonates due to the reaction that takes place between alkali hydroxides and the atmospheric carbon dioxide [24].
Generally, Si-O-Si and Si-O-Al stretching band appear at $1004 \mathrm{~cm}^{-1}$. Figures $10-12$ clearly show that the increase in the addition of $\mathrm{SH}$ concentration shifts the peaks towards lower frequency at $1004 \mathrm{~cm}^{-1}$, which is attributed to asymmetric stretching vibrations of $\mathrm{Si}-\mathrm{O}-\mathrm{Si}$ and $\mathrm{Si}-\mathrm{O}-\mathrm{Al}$ group present in the geopolymer concrete material $[26,27]$. Thus, the geopolymerization taken place by the addition of SH and SS to the FA and GGBS in all the ratios of samples taken has been confirmed.

\section{Conclusions}

The use of geopolymer concrete in the Indian context is not that much encouraging. The reason behind this is mainly due to the lack of codal provisions about the procedure for the design of geopolymer concrete. This is mainly due to lack of information about the basic properties of geopolymer concrete. This research addressed two issues: (i) effect of alkali activator on the standard consistency and setting times of geopolymer concrete and (ii) use of FA and GGBS, the industrial by-products in producing geopolymer concrete. Experiments were conducted on geopolymer paste with (a) varying percentages of FA and GGBS, (b) with varying molarity, $2.5 \mathrm{M}$ and $5 \mathrm{M}$ of $\mathrm{SH}$, and (c) with three different SH:SS ratios of $1: 1,1: 2$, and $1: 3$. XRF, SEM, and FT-IR analyses were carried out and the results are presented. The following conclusions have been drawn:

(i) While increasing the molarity of $\mathrm{SH}$, both consistency and setting times decrease.

(ii) For all the blended binder mix (FA-GGBS mix) consisting of various ratios, the initial setting time decreases with an increase in the concentration of SS in the AAS used

(iii) Increase in the amount of GGBS content in the geopolymer blended binder mix increases the consistency and decreases the setting times

(iv) For both $2.5 \mathrm{M}$ and $5 \mathrm{M}$ blended binder geopolymer mixes, a decrease in the percentage of GGBS and an increase in the percentage of FA increase the initial and final setting times

(v) From the SEM analysis, the lower molarity of SH and higher amount of FA (100\%) produce the unreacted FA in geopolymer paste

(vi) The FT-IR spectra for the blended binder mixes demonstrated the formation of geopolymerization and the presence of the functional groups

\section{Data Availability}

The data used to support the findings of the study are available from the corresponding author on request due to privacy/ethical restrictions.

\section{Conflicts of Interest}

The authors declare that they have no conflicts of interest. 


\section{References}

[1] M. Robbie, "Global $\mathrm{CO}_{2}$ emissions from cement production 1928-2017," Construction and Building Materials, vol. 10, pp. 2213-2239, 2018.

[2] S. Jena and R. Panigrahi, "Performance assessment of geopolymer concrete with partial replacement of ferrochrome slag as coarse aggregate," Construction and Building Materials, vol. 220, pp. 525-537, 2019.

[3] J. Davidovits, "Geopolymers," Journal of Thermal Analysis, vol. 37, no. 8, pp. 1633-1656, 1991.

[4] B. V. Rangan, Fly Ash-Based Geopolymer Concrete, Allied Publishers Private Limited, Mumbai, India, 2010.

[5] J. Davidovits, Properties of Geopolymer Cements, Scientific Research Institute on Binders and Materials, Kiev State Technical University, Mumbai, India, 1994.

[6] S. Sundar Kumar, K. C. Pazhani, and K. Ravisankar, "Studies on fly ash and slag blended geopolymer concrete," Journal of Structural Engineering, vol. 43, no. 3, pp. 301-310, 2016.

[7] P. S. Ambily, K. Ravisankar, C. Umarani, J. K. Dattatreya, and N. R. Iyer, "Development of ultra-high-performance geopolymer concrete," Magazine of Concrete Research, vol. 66, no. 2, pp. 82-89, 2014.

[8] P. S. Ambily, C. Umarani, K. Ravisankar, B. H. Bharatkumar, and N. R. Iyer, "Studies on ultra high performance concrete incorporating copper slag as fine aggregate," Construction and Building Materials, vol. 77, pp. 233-240, 2015.

[9] H. Kumar, R. Prasad, A. Srivastava, M. Vashista, and M. Z. Khan, "Utilisation of industrial waste (Fly ash) in synthesis of copper based surface composite through friction stir processing route for wear applications," Journal of Cleaner Production, vol. 196, pp. 460-468, 2018.

[10] D. Hardjito, S. E. Wallah, M. Dody, J. Sumajouw, and B. V. Rangan, "Factors influencing the compressive strength of Fly ash-based geopolymer concrete," Civil Engineering Dimension, vol. 6, 2004.

[11] N. Dave, A. K. Misra, A. Srivastava, and S. K. Kaushik, "Setting time and standard consistency of quaternary binders: the influence of cementitious material addition and mixing," International Journal of Sustainable Built Environment, vol. 6, no. 1, pp. 30-36, 2017.

[12] Central Electricity Authority: "Report on fly ash generation at coal/lignite based thermal power stations and its utilisation in the country for the year 2017-2018," 2018.

[13] P. Duxon, A. Fernandez-Jimenez, J. L. Provis et al., "Geopolymer technology: the current state of the art," Cement and Concrete Research, vol. 42, pp. 2917-2933, 2007.

[14] M. Nedeljkovi'c, Z. Li, and G. Ye, "Setting, strength, and autogenous shrinkage of alkali-activated fly ash and slag pastes: effect of slag content," Materials, vol. 11, 2018.

[15] J. J. Chang, "A study on the setting characteristics of sodium silicate-activated slag pastes," Cement and Concrete Research, vol. 33, 2003.

[16] P. Nath and P. K. Sarker, "Effect of GGBFS on setting, workability and early strength properties of fly ash geopolymer concrete cured in ambient condition," Construction and Building Materials, vol. 66, pp. 163-171, 2014.

[17] R. Alzeebaree and A. Omar, "Mechanical and durability properties of fly ash and slag based geopolymer concrete," Advances in Concrete Construction, vol. 6, pp. 345-362, 2018.

[18] M. ErenGüls_an and A. Radhwan Alzeebaree, "Development of fly ash/slag based self-compacting geopolymer concrete," Construction and Building Materials, vol. 211, pp. 271-283, 2019.
[19] A. Mohammedameen, M. E. Gülșan, R. Alzeebaree, A. Çevik, and A. Niş, "Mechanical and durability performance of FRP confined and unconfined strain hardening cementitious composites exposed to sulfate attack," Construction and Building Materials, vol. 207, pp. 158-173, 2019.

[20] P. Jangra, D. Singhal, B. Bhushan Jindal, M. Talha Junaid, and A. Mehta, "Mechanical and Microstructural properties of flyash based geopolymer concrete incorporating alcofine at ambient curing," Construction and Building Materials, vol. 180, pp. 298-307, 2018.

[21] M. M. Alonso, S. Gismera, M. T. Blanco, M. Lanzón, and F. Puertas, "Alkali-activated mortars: workability and rheological behaviour," Construction and Building Materials, vol. 145, pp. 576-587, 2017.

[22] I.S.:4031 (Part 4)-1988 (Reaffirmed 2005), Methods of Physical Tests for Hydraulic Cement Part 4: Determination of Consistency of Standard Cement Paste, Bureau of Indian Standards, London, UK, 1997.

[23] I.S.: 4031(part 5)-1988 (reaffirmed 2005), Methods of Physical Tests for Hydraulic Cement Part 5: Determination of Initial and Final Setting Times, Bureau of Indian Standards, London, UK, 2002.

[24] C. Ng, U. J. Alengaram, L. S. Wong, K. H. Mo, M. Z. Jumaat, and S. Ramesh, "A review on microstructural study and compressive strength of geopolymer mortar, paste and concrete," Construction and Building Materials, vol. 186, pp. 550-576, 2018.

[25] M. S. Morsy, S. H. Alsayed, Y. Al-Salloum, and T. Almusallam, "Effect of sodium silicate to sodium hydroxide ratios on strength and microstructure of fly ash geopolymer binder," Construction and Building Materials, vol. 39, pp. 4333-4339, 2018.

[26] A. Hassan, M. Arif, and M. Shariq, "Use of geopolymer concrete for a cleaner and sustainable environment-a review of mechanical properties and microstructure," Journal of Cleaner Production, vol. 223, pp. 704-728, 2019.

[27] P. Kumar, C. Pankar, D. Manish, and A. S. Santhi, "Study of mechanical and microstructural properties of geopolymer concrete with GGBS and Metakaolin," Materials Today: Proceedings, vol. 5, no. 14, pp. 28127-28135, 2018. 